\title{
Analysis of High Bride Price from a Cultural Perspective*
}

\author{
Manhong Si \\ School of Politics and Public Administration \\ Shandong Youth University of Political Science \\ Jinan, China 250014
}

\author{
Jing Wang \\ School of Marxism \\ Shandong University of Political Science and Law \\ Jinan, China 250014
}

\begin{abstract}
The bride price is part of the internal psychological structure of Chinese women's collective unconsciousness. Enhance women's social opportunity space and change the materialization tendency in women's culture, could gradually eliminate the collective unconscious setting of women's bride price, so that we could fundamentally solve the problem of high-value bride price.
\end{abstract}

Keywords-unconsciousness of national collective; female social opportunity space; materialization

\section{INTRODUCTION}

In general, the so-called bride price refers to the general term for all the property that the man's family pays to the woman's family from the match-making to the end of wedding feast. The bride price exists since ancient times, the man gave the woman a certain amount of property. It is not only the obedience to social customs, but also the blessings of the young men and women who are about to enter the marriage, it has the dual color of custom and emotion so it was understandable. However, in recent years, the high-valued bride price has become more and more popular, which has brought a heavy burden to the male family and affected the social atmosphere.

The issue of high-value bride price has gradually attracted the attention of the academic community since 2013, and the heat has increased year by year. The academic community generally believes that the high-value bride price phenomenon is not the result of any single factor, economic growth, the gender ratio of men and women, the trend of comparison, the values of money worship, and the intergenerational relationship are all related factors. However, there is a perspective that has long been ignored by us, that is, the bride price has been accumulated as part of the internal psychological structure of Chinese women's collective unconsciousness. Through in-depth analysis from this perspective, we find that by improving women's social opportunity space and changing the tendency of materialization in women's culture, we can gradually eliminate the collective unconscious setting of women's bride price, and fundamentally solve the problem of high-value bride price.
This is meaningful for both the development of men and women and the overall progress of society, and it is also conducive to improving the degree of emotional purity of marriage and love.

\section{High-VAlue: ANALysis OF THE TENDENCY OF BRIDE PRICE AMOUNT}

The literature survey found that although the per capita annual income varies greatly across the country, the ratio of the fees paid by marriage to the per capita income is fixed, and it takes about ten years of per capita income to bear.

Li Yinhe pointed out in her book "Fertility and Village Culture" that in Heilongjiang Province: "Nanshantou Village has an average annual income of 332 yuan and a marriage cost of 3,000 yuan, that is, 10 years of income for one person could afford one wedding; The annual income of Nanyang Village is about 2,000 yuan, so the wedding expenses raise to 15 to 20 thousand yuan, which is equivalent to a person's income of about 10 years".[1]

According to a survey by Professor $\mathrm{Na}$ Yulan of the National Normal College of Qinghai Normal University, in Xiakou Village of Qinghai province, the marriage process is complicated, including match-making, blind date, house inspection, gift affirmation, gift-giving, date confirmation, wedding and so on. According to local customs, the man family needs to pay different amount of money or items to the woman's family. The local per capita annual income is less than 1,000 yuan, and the money given by the blind date is from about 400 yuan in the 1990 s to about 800 yuan in the first 10 years of the 21 st century, up to now around 1,300 yuan. The gift of gift affirmation is also a cash gift, from 3000-6000 Yuan in the 1990 s to 30,000 to 60,000 now. It takes about 10 years for a family to get enough money for a son to get married. Before the marriage, the Lantern Festival, February 2nd, April 8 th, and June 6th they also have to give the woman holiday money from 200 to 500 yuan. There is also a final wedding feast that costs more than 2,000 yuan. In the process, women's clothes, jewelry, cosmetics and other items need be also provided by the man's family. If there is a son in the family

*This article is one of the research results of University Humanities and Social Sciences project in Shandong Province "The research on the evolution and reconstruction of contemporary festival folklore in the version of scientific field" (Project No. J13WA02). 
who gets married, it will take more than ten years to get the money and gifts enough. ${ }^{1}$

Coincidentally, Professor Tian Feng from the Teaching Department of Ideological and Political Theory of Tianjin University of Sport conducted a sample survey of 18 townships in Datian County, Fujian Province through questionnaires, interviews, and files checking. He found that the amount of Datian County's bride price was mainly concentrated at 60,000 -160,000 yuan." [2] It is also equivalent to the income of local ordinary farmers for about ten years.

\section{LONG History: THE HISTORICAL TRACE OF THE BRIDE PRICESTYLE}

In the long process of Chinese history, the custom of bride price has been formed for a long time. When the form of marriage was changed from follow the wife's residence to follow the husband's residence, the custom of bride price emerges as the times require. In the traditional Chinese society, after the implementation of follow the husband's residence, the woman married to the man's family and gave birth to the man's children and handled family affairs, it is difficult to make a substantial contribution for her own family. In order to give the woman's family certain compensation, the folk custom of bride price has formed.

In ancient times, people were living in their nature and easy to be unrestrained in terms of sexual relations. For that reason, Zhou Gong introduced emotions into rituals, thus the marriage stylization began to form, the marriage ritual then has the saying of "six parts", respectively, "Na Cai", "Wen Ming", "Naji", "Na Zheng", "Qing Qi", "Qin Ying". The man sends bride gift to the woman is the "Nan Zheng" in the "Zhou Gong Liu Li". The amount of early gift was small, mostly for practical use or symbolic items. For example, in the "Yi Li Shi Hun Li", the Xuanpiao, Shubo, and Lipiin the bride gift are required to be paired, symbolizing the completion of yin and yang and a harmony marriage. In the pre-Qin period, the items such as sheep, geese, quails, and lacquer in the bride gift all have the meaning of blessing the newlyweds.

Since the Han Dynasty, the bride price style has prevailed, from Royalty to the small citizen all the same. At the beginning of Han Dynasty, the national strength was not strong. According to Du You's record in the "Tong Shu", when Emperor Han Hui emperor married Princess Lu Yuan, "He sent 20,000 jin of gold, 12 horses". From there it passed along as a custom and the folk marriage is like this as well. The cost of a wedding is huge, often "rich people are heavily reduced their wealthy" and the "poor people are in loans", which leads to the prevalence of luxury in the society. The poor people cannot marry because they cannot afford large-scale bride price. At the same time, it affects the quality of marriage at a certain level, "A mother loves gold, and a brother wants to ride a horse. So my little girl will marry to some players".[3]

During the Wei, Jin and Southern and Northern Dynasties, the high-value bride price style became more and more serious.

Yulan: An Analysis of the High-Valued "Bride price" in Hehuang Village- Taking Xiakou Village in Qinghai Province as an Example, Qinghai Ethnic Studies, No. 1, 2015.
Yan Zhitui, the famous litterateur of the Northern Qi Dynasty, pointed out painfully in his famous "Yan Shi Jia Xun. Zhi Jia": "In recent times, the marriage is almost like sell daughter for money, they count every coin for the bride price, argue and blame for each other about the bride price."It made a comprehensive description of the social situation that ritual and materialization tendency of "Nanzheng" is becoming more and more serious, he believed that is completely deviated from the Zhougong ceremony when he was trying to express the importance of marriage through the "Liu Zheng" and the initial will of the good blessing of the marriage people.

This materialization tendency has become more and more serious, causing a very bad social impact, so that the emperor begun to actively intervene. Emperor Qi Wudi, the second emperor of the Southern Qi Dynasty, pointed out in the script that the high-value bride price style has made the social atmosphere increasingly extravagant, he required relevant departments to advocate a new thrifty style of marriage in the whole society. "The rich people should contain their arrogance, and the poor people are ashamed to not able to provide as they promised. If they do not have all the bride gifts ready, they will postpone the wedding. But time will not go back, if you passed the best marriage time, it will gone forever. So the wedding should be thrifty and no matter officers and normal people should be the same". [4] The third Emperor Wudi of the Northern and Southern Dynasties also claimed that "The government is saving money, so the rituals and ceremony should be thrifty. But the married family spent all their wealth to compete the luxury trend, it is disobey the ancient ritual. So the relevant departments should promote the law and ask them to obey the ancient rituals". [5] He blamed the high-value bride price style is not only cost a lot of fortune, but also violate the fundamental spirit of ritual system.

In order to contain the high-value bride price style, the Wei, Jin, Southern and Northern Dynasties set strict bride price specifications according to different levels of society. "For Princes, the bride gifts include one bolt of Yuan, two bolts of reel, ten bolts of silk, one piece of big jade ornament(officers from the first-rank to sub third-rank use flat jade plate, officers below fourth-rank did not include jade), two pieces of animal skin (officers from first-rank to sub fifth-rank use leopard skin, from sixth-rank to sub ninth-rank use deer skin), sixty bolts of colored brocade (officers of first-rank is forty bolts of colored brocade, second-rank is thirty bolts, third-rank is twenty bolts, fourth-rank is sixteen bolts, fifth-rank is ten bolts, six and seventh-rank is five bolts), two hundred bolts of thin silk ( officers of first-rank is one hundred and forty bolts, secondrank is one hundred and twenty bolts, third-rank is one hundred bolts, fourth-rank is eighty bolts, fifth-rank is sixty bolts, sixth and seventh-rank is fifty bolts, eighth and ninthrank is thirty bolts), a lamp, four sheep, two calf, wine, millet, shu, dao, rice, flour each for ten hu (officers from first to thirdrank reduce to two sheep, and wine, mellet, shu, dao, rice, flour each reduce six hu, fourth-rank reduce one calf and reduce two more hu of wine, millet, rice, shu, dao, and flour, officers below six-rank has no calf, wine, millet, dao, shu, rice, flour each for one hu)".[6] Jade, silk fabrics, daily necessities that required for the bride gifts has detailed and differentiated regulations according to the different classes of the married 
family. But even with the strong intervention of national government, the high-value bride price trend is still prevalent.

The high-value bride price style was also extremely serious in Yuan Dynasty, Zheng Jiefu of Yuan Dynasty pointed out in the 6th volume of "Li Dai Ming Chen Zou Yi" that "The married is all about ask for money which is no different with livestock selling" This trend has affected the marriage rate, "because if the bride price is too low, then they cannot get married"[7], especially the marriage rate of men and women in marriage-appropriate age, "they lost the married time" [8]. In order to change this tendency, from family to country all actively try to solve the problem. Such like the $\mathrm{Lu}$ family, known as "The first family in East Zhejiang Province", has set up a "Jia Li Zhuang" for the family's young people, "Established one Jia LiZhuang, with the area of one thousand and five hundred mu, and it was increasing along with the times, the land was rented for money and operated by talent people in the family, the eared money will be the bride price and wedding fee for both men and women, each one with a hundred and fifty Dan grain as the principle".[9] At national level, the Yuan Dynasty set the basic criteria for bride price for people from the beginning of Yuan Dynasty, such like the 8th year of Zhiyuan, the standard bride price promulgated by the Ministry of Housing is "For officers: First and second-rank officers is five hundred Guan, third-rank officers is four hundred Guan, fourth, fifth-rank officers is three hundred Guan, sixth, seventh-rank officer is two hundred Guan, eighth, ninth-rank officers is one hundred and twenty Guan. For common people: Upper class people is one hundred Guan, middle class people is fifty Guan, lower class people is twenty Guan"[10]. And with the price increase in the middle of Yuan Dynasty, it made corresponding adjustments. In the Dade period of Emperor Yuan Chengzong, a new bride price system was promulgated, "For upper class people, it is one liang of gold, five liang of silver, six bolts of stain silk, and forty bolts of thin silk; For middle class people, it is half liang of gold, four liang of silver, six bolts of stain silk and thirty bolts of thin silk; For lower class people, it is three liang of silver, two bolts of stain silk and fifteen bolts of thin silk".[11] The introduction of this series of policies and measures reflect the severity of the high-value bride price style at that time on the other aspect.

The traditional society is willing to accept a large amount of bride price, because in the social background of that time, marriage is not a private matter of young people, but a marriage between the two families. The amount of bride price is related to the two families' status and prestige in the local area especially for the man's family, the son's wedding is a big family event that is "serve up to the temple of the ancestor, and down to the next generation" ("Li Ji. Hun Yi"), so it cannot be ignored. Not only that, the wedding also has important ethical significance, in the traditional culture, sex is the beginning of human relations, "Zhou Yi. Xu Gua" said: "Earth grows nature, nature raises men and women, men and women married into couple, couple relationship grows father and son, father-son relationship grows monarch-subject relationship, there are monarch-subject relationship and then there are up and down, there are up and down and then the there are differences in rituals". So the two family get married is an important event with a profound ethical background are good in ancient traditional society, no one will be sloppy, which has also boosted the prevalence of high-value bride price style from a certain level.

\section{NATIONAL UnCONSCIOUSNESS: THE PSYCHOLOGICAL GENERATION OF High-VALUE BRIDE PRICE}

The high-value bride price style has a long history, and it has been a long-lasting since the Han Dynasty. The politicians of the dynasties also stopped it from national level, but the results are minimal. What is the reason? This must have a deeper psychological or practical reason as the basis, so that the high-value bride price styles are so vital.

\section{A. The National Inner Psychological Structure Concerning the Bride Price}

In "Li Ji, Nei Ze", it is said: "Betroth a wife, elope a concubine". In ancient society, under the strong patriarchal structure, the ultimate acquisition of social and family identity for women is not based on the status of the wife's family, but relies on the identity and status of the husband. For women in traditional societies, this is almost the only chance that most women have to gain social identity in their lifetime. In this sense, women gain self-identification and thus have a legitimate identity, and bride price plays a role that cannot be ignored. It is not difficult for us to understand why women are pursuing bride price and even high-value bride price, it is to obtain their identity recognition in marriage and family, and thus gain a sense of recognition and security.

Liu Xiang, a scholar of the Western Han Dynasty, recorded in "Lie Nv Zhuan" about several women who attached great importance to the wedding ritual, such as Wei Quwo Fuzhao Nanshen Nv, Qi Xiao Meng Ji, Qi Su Liu Nv, etc. These women were obsessed with the wedding ritual, if the gift is not well prepared, they would rather die than get married", ("Lie Nv Zhuan. Qi Su LiuNv") it has confirmed the rationality of the above discussion from sideways.

For women, bride price is the acquisition of a reasonable identity of social marriage and the recognition from male's family. The bride price plays a very important role in the acquisition of women's marriage security and the confirmation of women's social identity. The ritual of "Liu Zheng" was established from the beginning of Zhou Dynasty and finished until the establishment of the new China, which was almost accompanied by the long historical stage of the Chinese nation. Such a long-lasting social etiquette and corresponding cultural construction make the women of Chinese nation have different psychological attitude compared with women of other ethnic groups. This psychological attitude is established through unconscious forms such as conscious cultural education, customs, and ethics. That is to say, after a long period of history, Chinese women's mentality of obtaining marriage security and male family recognition through bride price has become a collective unconsciousness of all women. It has become an intrinsic psychological operating mechanism which sediment in the hearts of Chinese women, know what but not know why, but works through a potential dimension. 
Therefore, until today, although the family identity of each woman can be confirmed by government-issued documents, the collective unconsciousness of obtaining family marriage psychological security through bride price has already been formed, and it has become a deeply potential inner psychological need of women. Once the national collective unconsciousness has formed, it has the characteristics of a fixed trend, that is, it has a fixed and restrictive role in the subsequent psychological situation. Hoped that it will disappear completely in a short period of time is undoubtedly violates the basic laws of psychology and is difficult to achieve. In the collective unconscious formed by this powerful history, it is unbelievable to not ask or ask for less bride price. For women in contemporary society, this is not a formal social recognition, but it represents the recognition degree of male families. Women's pursuit of bride price in fact reflects a relatively weak social psychological position of women in male society.

That is to say, since the founding of the People's Republic of China, although women's social and economic positions have made great progress, the existence of women's relatively weak marriage culture is still an undeniable fact. The pursuit of high-value bride price is a weak inner psychological need. It can give women a sense of recognition, satisfaction, and security. If we ignore the long-term historical influence and do not eliminate the social reasons, it is unreasonable and impossible to simply change the requirements of the customs.

If a social phenomenon wants to be truly presented, it needs the internal psychological structure of the nation as a mechanism for germinal development, it also needs external social economic and cultural conditions to support it in order for it to realize. What are the socio-economic and cultural foundations for the formation of high-value bride price?

\section{B. Social Conditions Presented in the National Inner Psychological Structure}

The realistic basis for the formation of high-value bride price is the general growth of family wealth since China's reform and opening up, which provides material conditions for the maintenance of high-value bride price. By 2015, China's total family wealth reached 35 trillion US dollars, second only to the United States.

In today's China, the absolute increase of women's status and the relative weakness are the true portrayal of the gender position of women. This situation also stimulates the renewal of high-value bride price. At this time, the pursuit of highvalue bride price by women is stimulated by the national collective unconsciousness, which is a kind of compensation psychology of women for their relatively weak social economy, politics and family status. .

Marxist concept of marriage and family is instructive to us. Marxist discourse on marriage and family is concentrated in "Morgen 'Ancient Society' Book Abstract" and "The Origin of Family, Private Ownership and State". In Marxism, all changes related to marriage cannot be stopped in the limited vision, and it should be interpreted in terms of the state of production as a whole and the status of women in social production. "Religion, family, country, legal power, morality, science, art, etc. are just special ways of production, subject to the general law of production".[12] In this sense, if we do not pay attention to the position of women in social production, we do not pay attention to the position of women in economic life, just simply talk about the issue of bride price does not make sense.

From the "2016 Global Gender Gap Report", we can see that Chinese women need to go a long way in achieving economic equality with men. "The East Asia and Pacific region ranks fifth in the region where the gender gap is narrowing. The contrast in the region is very clear, and the gender-equitable societies such as the Philippines and New Zealand have a big difference with the several economic power countries such as China (99th) and Japan (111th). South Korea (116th)". Relevant predictions indicate that it will take more than a hundred years to truly eliminate the economic disparity between men and women in the region.

Specifically, in terms of Chinese women's ownership of production capital, the second phase of Chinese women's survey data shows that $10.8 \%$ of rural women in the country have no land, more than two times of male's $5.1 \%$. This data looks good on the surface, which means that $90 \%$ of women own land. But in reality, these lands are either dominated by fathers within the family as unmarried women or by husbands as married women. The proportion of women in the country who truly control land ownership is not high.

The employment situation of Chinese women is as follows: "The employment rate of women in China is high, but the quality of employment is not high. Statistics show that female professionals in China account for only $5 \%$ of all women employed. Most women employed are still simple labor force. In terms of professions that need higher culture and technology, the proportion of women is lower".[13] It can be seen that the position of women in social production is low. Women have less room to rise in their work. According to the "2014 China Labor Statistics Yearbook", in 2013, among the national employment status, the number of employers among women accounted for $2.6 \%$ of the total number, and the corresponding data in the male population is $5.2 \%$.

From the overall society level, Chinese women are relatively weak in politics, economy, education, law, employment, and health. Due to the relatively weak position in society, the status of women in the family is also very low, and the economic wealth brought to the family is small. The majority of the marriage model is husband dominant, and the children have more significance of patriline families.

There is another example to prove that women are in a weak position in social life and marriage, that is, the longstanding male preference in Chinese society during the birth process. American scholar Meade Cain once pointed out that the son preference is essentially the low status of women, and it is caused by women's economic dependence on men. ${ }^{2}$ (Cain, 1993) China has now formed a gender imbalance, and the sixth census shows that the male-female ratio is $105.2: 100$. It is estimated that by 2020, China's marriage-age males will be 30

2 Zhuang Yuxia: "A level Deduction of the Women's Low Status An Analysis of the Hidden Images of the higher Sex Ratio at Birth", Southern Population, No. 1, 2006. 
to 40 million more than women. It illustrates the male preferences of Chinese society and also shows the low status of women in Chinese society.

Undoubtedly, women have a closer relationship with their children after marriage, and will bear more family responsibilities for helping the elderly, and raising the children, along with that, social competitiveness will have a more obvious reduction than before marriage. According to the "2014 China Labor Statistics Yearbook", 36.8\% of women lost their jobs because they had to do housework, and the proportion of men who lost their jobs for the same reason was only $4.1 \%$. Faced with the resource possession that is scarce in the economy, politics and culture in the future, faced with the bleak future of men, how can women not have a greater advantage in the marriage market with the only bargaining power? This is also an important reason for the emergence of high-value bride price.

In summary, the high-value bride price is a kind of selfrescue of social status and marital status that women spontaneously rise up under the inspiration of the national unconsciousness. Therefore, under such circumstances, if a woman is able to obtain a bride price higher than average value, she will be considered to be more powerful and will gain more respect in same-sex relationships.

\section{External Cultural Conditions Presented by the National Psychological Structure}

Marxist view of marriage and family believes that marriage and family are accompanied by men's suppression of women, "Individual marriage system has never appeared as reconciliation between men and women in history... On the contrary, it is as one sex been enslaved by another sex, and it appeared as the announcement of two-sex confrontation in prehistoric era". [14] Marriage and family will change their form with the development of society until the goal of equality between men and women is achieved". Regard to the modern monogamous family, it must develop with the development of society and change with the changes of society, just like it used to be. It is the product of social system... We can imagine: it can still be better improved until the equality between the male and female is reached". [15]

The high-valued bride price also indicates a change in the relationship between men and women. On one hand this aspect means that women have higher material value, but on the other hand, it means that no matter how high value the bride price women received, it still exist with object form and the value form of objects, and the female's subjectivity in the marriage process is still not fully presented.

We have defined the materialization attributes of women for so long. One of the theories on bride price is widely accepted, that is, the famous theory of marriage repayment. The most prominent feature of this theory is the commercialization of women. In Marxism, every commodity has both value and use value, and it is a dialectical unity of value and use value. Women are commodities in the marriage market, so women this commodity has both value and use value. The use value of bride this commodity expressed as her arrival will bring the reproduction of labor force to the male family. The value of bride this commodity is expressed as the sum of the various costs paid by the woman's family to raise her. The price of the bride is determined by the value of bride this commodity and is changed by the supply and demand influence of the marriage market. In the "family history" of the French sociologist André Bilkier, it directly uses the concept of bride price. In the East Liaoning region of China, the bride price is also directly called "raising money". The theory of marriage payment has been widely spread and applied, and it also shows that we have a social and cultural foundation that is universally accepted for the positioning of women's materialization or commercialization.

The gender culture of women's materialization has long been deeply rooted in people's hearts, which eventually led to the psychological state of women's self-materialization. Selfmaterialized women will ask for more bride price when they see the bride's scarcity in the marriage market. Sun Shumin pointed out in the book "The Peasant's Choice of Mate - An Empirical Study of Zhao Village in the Northwest", if the woman's family does not ask or ask for less bride price, "not only it may cause the speculation about the daughter "has problem', but may cause the contempt for send the daughter "to others for free"'. This is actually a realistic representation of the definition of female materialization for a long time, equating the bride price as the selling price of the commodity, so if the bride price is lower than the social average level, then there will be a psychological imbalance that sells the bride commodity at low prices.

\section{CONCLUSION}

In short, analyze the current high-value bride price phenomenon, bride price as recognition of women's identity, this national collective unconsciousness has become a deep psychological picture of Chinese women, and automatically play a guiding and restrictive role. After the reform and opening up, the increase of family wealth provided material security for the realization of high-value bride price. The promotion of women's position in the absolute sense and the weak position in the relative sense further stimulate women's sense of marriage and family security through bride price, and grasp the compensation psychology of more social wealth. Under the help of the self-materialized feminine culture, the high-value bride price phenomenon has a richer and more complex internal structure.

In this sense, simply criticizing the phenomenon of highvalue bride price, only makes a relatively shallow level of exploration to solve this problem. In a more in-depth sense, we must fundamentally change the relatively weak social status of Chinese women, provide more social opportunities for women, and make women more powerful. If our society provides women with gender opportunities comparable to men, and women have more social opportunities to improve their social status and family status, women do not need to be inspired by the national collective unconscious to obtain higher society family security and control power through high-value bride price.

On the other hand, we should pay attention to the connotation of women's culture, do more and more humanized 
connotation construction of women culture, and get rid of the materialized meaning of women's self-setting. Of course, this is not only the task of scholars, but every woman must also complete self-growth at the level of spiritual life. Only after we have made a practical exploration in social culture, in time, the national psychological set of women who make self-recognize through dowry will slowly disappear. The simple vision of the return of bride price that we desired for emotional blessing will be truly achieved.

\section{REFERENCES}

[1] Li Yinhe. Fertility and Village Culture [M]. Inner Mongolia: Inner Mongolia University Press, 2009. 36-37.

[2] Tian Feng, Chen Zhenbian. Analysis of the Problem of High-value bride price of Rural Youth Marriage - Taking Datian County of Fujian Province as an Example[J].China Youth Social Science.2016(2).

[3] Quan Tang Shi [M]. Beijing: Zhonghua Book Company Press, 1992. 865 .

[4] Third Volume of Nan Qi Shujuan Sanbenji- Emperor Wu Di. [M]. Beijing: Zhonghua Book Company Press, 1972.

[5] Fifth Volume of Zhou Shu Juan-Emperor Wu Di [M]. Beijing: Zhonghua Book Company Press, 1971.

[6] (Tang) Wei Zheng. Sui Shu [M]. Beijing: Zhonghua Book Company Press, 1973.179.

[7] (Yuan) Wang Wei. 35th Volume of Qiu Jian Ji-Shang Shi Zu Huang Di Ren Zheng Shi Shu[M]. Photocopying of Wenyuange Sikuquanshu.

[8] (Yuan) Wang Wei. 86th Volume of Qiu Jian Ji-Lun Li Pin Cai Shi Zhuang[M]. Photocopying of Wenyuange Sikuquanshu.

[9] (Yuan) Zheng Wenrong. Zheng Shi Gui Fan [M] Article 74. Zhengzhou: Zhongzhou Ancient Books Publishing Company, 2015.

[10] The 18th Volume of Yuan Dianzhang-Jia Qu Pin Cai Ti Zhi [M]. Haiwangtun ancient books series.

[11] The 3rd Volume of Tong Zhi Tiao Ge Jiao Zhu-Hun Yin Li Zhi [M]. Beijing: Zhonghua Book Company, 2001. 39.

[12] (German) Marx, Engels. 42th Volume of Marx and Engels Complete Collection [M]. Beijing: People's Publishing Company, 1979. 121.

[13] Edited by the Office of the Women and Children's Work Committee of the State Council. "Chinese Women's Development Program (20012010)" study counseling. Beijing: China Women's Publishing House, 2002. 26.

[14] (German) Engels. Family, private ownership and the origin of the country. Beijing: People's Publishing Company, 1972. 62.

[15] (German) Marx. Abstract of Morgan (Ancient Society). Beijing: People's Publishing Company, 1970.45-46. 